\title{
The medical ethics of physician-assisted suicide
}

Tom L Beauchamp Georgetown University, Washington DC, USA

Absolute prohibitions of physician assistance in suicide have long been canonical in medical ethics, but a powerful reformation of views on euthanasia and physician-assisted suicide is now underway in several countries. The law on physician-assisted suicide in the state of Oregon, social approval of euthanasia in the Netherlands, and the (in principle) legality of active euthanasia in Japan are clear signs of the future. The key moral issue that will drive discussion is the liberty to choose the means to one's death and the justification, if any, for limiting that liberty.

Until very recently the consensus view in most countries was that a passive euthanasia of letting die is acceptable, but an active euthanasia of killing is not. An extraordinary transformation in our conception of the role of patient autonomy had occurred to bring about this consensus. We migrated from a fear of any form of intentional hastening of death to a confidence that it is permissible under a variety of conditions intentionally to forgo life-sustaining technologies of all types, knowing that death will ensue.

This history is now shifting from refusal of treatment-where the consensus was originally formed-to request for aid that involves physicians (or other second parties). The issues of first-party refusals of life-sustaining technologies are behind us. The issues are now about how patients will be able to request aid. My concern here is not with issues of legalisation or appropriate public policy. I want to suggest why certain acts that have traditionally been considered mercy killings are better framed as forms of requested aid-in-dying. The term "killing" has done more to confuse than to clarify thinking about these matters. None the less, killing remains the centrepiece of the current discussion.

\section{Killing and letting die}

The influential distinction between killing and letting die is essential to the traditional view that killing (even at another's request) is prohibited and letting die permitted under specified conditions. However, the multi-purpose term "killing" does not entail a wrongful act or a crime, and there are several generally accepted justifications of killing, such as killing in self-defence and killing to rescue a person endangered by the immoral acts of other persons. Correctly to apply the label "killing" or the label "letting die" to a set of events will therefore not determine whether the set of events is morally acceptable or unacceptable. This is as true in medicine as elsewhere. Killing may typically be wrong and letting die rarely wrong, but this conclusion is contingent on the features of particular circumstances, not merely on whether the act is a killing or a letting die.

This result is not surprising inasmuch as killings are rarely authorised by appropriate parties (excepting capital punishment), whereas cases of letting die generally are authorised appropriately. $\mathrm{Be}$ that as it may, the frequency with which one kind of act is justified, by contrast to the other kind of act, is not relevant to the moral (or legal) justification of either kind of act. Forgoings that let a patient die can be both as intentional and as immoral as actions that involve direct interventions to bring about death (and both can be forms of killing).

Furthermore, the killing/letting-die distinction is largely irrelevant to today's mainstream issues about physician-assisted suicide, because the cases are not ones in which physicians are involved in either killing or of letting die. For example, a physician who prescribes a lethal medication at a patient's request does not thereby cause the patient's death and neither kills the patient nor lets the patient die, whether or not the patient voluntarily ingests the medication and dies.

A common thesis is that "letting die" occurs in medicine by "ceasing useless medical technologies", but "letting die" actually occurs in medicine under two circumstances: one is the cessation of medical technology because it is useless and the other is the cessation of medical technology 
because it has been refused. Honouring a refusal of a useful treatment knowing of a fatal outcome is letting someone die, not killing the person. The type of action-a killing or a letting die-can thus depend entirely on whether a valid refusal justifies the forgoing of medical technology. If there is no valid refusal, the act is an unjustified killing; if the act is of an identical type but is underwritten by a valid refusal, it is a justified letting die.

The received account of letting die in both law and medicine relies on a doctrine about the causation of death. The thesis is that intentionally forgoing a medical technology qualifies as letting die, rather than killing, if and only if an underlying disease or injury causes death. Despite its venerability, this received view is unsatisfactory. To obtain a satisfactory position, it must be added that the forgoing of the medical technology is validly authorised and for this reason is justified. Otherwise, allowing a "natural" death would be a killing. Again we see the absolutely central conceptual and moral role of valid authorisation.

In many cases of justified withdrawing or withholding of a medical treatment, death is not caused by an underlying condition of disease or injury. For example, an act of removing a nasogastric tube to abate hydration or nutrition leads to death from malnutrition, not death from an underlying condition of disease or injury. The disease or injury motivates and justifies the decision to forgo treatment, but does not cause death.

From both a legal and a moral point of view, one reason why physicians do not injure or maltreat patients when they withhold or withdraw medical technology (often with the intention of bringing about death) is that physicians are morally and legally obligated to recognise and act upon a valid refusal, irrespective of the causal outcome of doing so. Since a valid refusal of treatment obligates the physician to forgo treatment, it would be absurd to hold that these legal and moral duties require physicians to cause the deaths of their patients - in the legal and moral sense of "cause"-and thereby to kill them.

The particular form or mode of causation of death is not therefore the material matter in the justification of assistance in dying by forgoing treatment. As long as a refusal of medical technology is valid, there exists no problem about responsibility for the death that ensues or about the justification of the action.

\section{Valid refusals and valid requests}

The issue of valid requests for active assistance in dying is more difficult than these issues about valid refusals of treatment, but consider the logic of the law on physician-assisted suicide in Oregon a valid request for assistance removes legal culpa贲 bility for the death that is arranged, but in the absence of a valid request, the same act is one of. killing, indeed murder. This logic is why oppo $\overrightarrow{\vec{F}}$ nents of that law so deeply abhor it. It underwrite 5 the principle that valid requests for assistance legitimate responses by physicians to suctop requests.

Of course, refusal and request are not so alike that the physician must act on whatever the patient or family wishes. Whereas a health professional is obligated to honour a refusal, he or she i⿸ not obligated to honour a request. Valid refusal obligate a physician to do something (or forbeap from doing something) that leads to deathis whereas valid requests only make it permissible for a physician (or some other person) to lend aid in dying. A physician who in principle accepts the permissibility of assistance in bringing about death may still refuse to honour a particular request if there is good moral reason for doing soo

Causing a person's death is morally wronge when it is wrong, not merely because the death iह caused by someone, but because an unauthorise雨 and unjustified harm or loss to the person occurseco The death is bad for the person only if there isgire unauthorised and unjustified deprivation of opportunities and goods that life would otherws have afforded. If a person freely elects and author ises death and sees that event as a personaf benefit, rather than a setback, then meeting the person's request involves no clear harm or mora wrong.

If letting die based on valid refusals does not harm or wrong persons or violate their rights, how? can assisted suicide or voluntary active euthanasit harm or wrong a person who dies? In each cased persons seek what for them in their bleak circum? stances is the best means to the end of quitting life. Their judgment is that lingering in life is worse than death. The person in search of assisted suicide, the person who seeks active euthanasias and the person who forgoes life-sustaining tech nology to end life may be identically situated They simply select different means to the end ofs their lives.

\section{Looking to the future}

In the twenty-first century we can expect th following to happen: the laws or precedent $\$$ permitting physician-assistance in death will proved manageable and even be improved in the Nethero lands, Oregon, Japan, and other locations. In the meanwhile, law, ethics, and medicine will struggl $\frac{8}{8}$ to find more conservative alternatives. 
One option will be the cultivation of a wider array of circumstances under which competent patients are allowed to refuse nutrition and hydration in order to end their lives. The refusal of nutrition and hydration appears to encounter no legal or moral problems in many countries, despite the fact that there is no clear distinction between starving oneself to death and suicide or between a physician's starving a patient to death at the patient's request and physician-assisted suicide. The other option that is certain to come into increased favour is a dramatically improved style of palliative care. There is already a consensus that better end-of-life care, including palliative care, is needed, and we can expect to see more resources and training in support of this commendable goal.
No one of these three different options: (1) provision of fatal means to death, (2) planned forgoing of nutrition and hydration, and (3) improved palliative care will necessarily be best for each patient. The presentation of these options is also consistent with the larger argument I have presented, which is that these issues of euthanasia, physician-assisted suicide, and aid-in-dying are primarily about increased liberty, not about killing and letting die.

Tom L Beauchamp is Professor of Philosophy at the Kennedy Institute of Ethics, Georgetown University, Washington DC, USA.

\section{News and notes}

\section{Fifth World Congress of Bioethics}

The International Association of Bioethics has announced that the Fifth World Congress of Bioethics will take place at Imperial College, London from 21-24 September 2000.

Associated organisations are: The British Association for the Advancement of Science; the British Medical Association; the European Association of Centres of Medical Ethics; the Institute of Medical Ethics; the Millenial Festival of Medicine; the Nuffield Council on Bioethics; the Royal College of Nursing; the Royal
College of Psychiatrists, Philosophy Special Interest Group; the Society for Applied Philosophy; the UK Forum for Healthcare Ethics and Law, and the World Health Organisation.

For further information please contact: Sara Hassen, 5th World Congress of Bioethics, 1 Riverside, St Anne's Road, Bristol, BS4 4ED or email: enquiries@inanyevent-uk.com or use the Congress Website at http://www.uclan.ac.uk/facs/ethics/fifthcon. htm 